\title{
Un pequeño sonido de amor
}

\author{
A SMALL SOUND OF LOVE
}

UM PEQUENO SOM DO AMOR

Gisela Mariana Farias López*/ gimafalo_chivas@hotmail.com

\section{Resumen}

Este escrito no es solo un relato, se convirtió en una de las experiencias y retos más importantes que he enfrentado. Mi vida personal y profesional como docente dio un giro total al conocer a Alex, un niño con Síndrome de Asperger; darme cuenta de que existen seres tan diferentes, que muchas veces ignoramos para hacernos la vida más cómoda y que, sin embargo, están llenos de tantas enseñanzas, solo se necesita un poco de paciencia e imaginación, pero, sobre todo, humanismo. Haber compartido sus temores y diferencias, poder imaginar que un tambor me ayudaría a enseñarle a contar, unos fríjoles de colores a sumar, una grabadora a conocer su talento para la música, y que tocando su pecho escucharía lo primero de su lenguaje, un: "bum, bum, maetla”, que para mí significó ese pequeño sonido de amor. Compartir algunos días de su vida y sumergirme en un mundo tan diferente del mío, uno que aún sigo sin comprender por completo; vivir junto a él uno de los hechos más dolorosos de su vida: la muerte de su madre, y muchos momentos más, son el contenido de este relato; su aprendizaje se convirtió en mi meta y mis miedos en aprendizajes.

\section{Summary}

This writing is not just a story, it became one of the most important experiences and challenges they have faced. My personal and professional life as a teacher gave a total turn when she meets Alex, a child with Asperger's Syndrome; realize that there are so many different things, often ignore to make our life more comfortable and which, however, are filled with many teachings, just need a little patience and imagination, but above all, humanism. Sharing their fears and differences, to imagine that a drum help me teach counting, some beans add color to a recorder to know his talent for music, and touching his chest hear your first language, a: "bum, bum, maetla" which for me meant that little sound of love. Share some of your life and dive into a world so different from mine, one that I still do not fully understand; live with him one of the most painful events of his life: the death of his mother, and many more moments, are the content of this report; learning became my goal and my fears in learning.

\section{Resumo}

Esta escrita não é apenas uma história, tornou-se uma das experiências mais importantes e os desafios que enfrentaram. A minha vida pessoal e profissional como professor deu uma volta total, quando ela conhece Alex, uma criança com Síndrome de Asperger; perceber que existem tantas coisas diferentes, muitas vezes ignoram para tornar a nossa vida mais confortável e que, no entanto, são preenchidos com muitos ensinamentos, só precisa de um pouco de paciência e imaginação, mas, acima de tudo, o humanismo. Compartilhando seus medos e diferenças, imaginar que um tambor de me ajudar a ensinar a contagem, alguns grãos de adicionar cor a um gravador de conhecer o seu talento para a música, e tocando seu peito ouvir a sua primeira língua, a: "bum, bum, maetla" que para mim significava que pouco som do amor. Compartilhe alguns de sua vida e mergulhar em um mundo tão diferente do meu, que eu ainda não entendo completamente; viver com ele um dos eventos mais dolorosos da sua vida: a morte de sua mãe, e muitos mais momentos, são o conteúdo do presente relatório; aprendizagem tornou-se o meu objetivo e meus medos na aprendizagem.
Palabras clave

Docente, Síndrome de Asperger, narrativa, inclusión.

\section{Keywords}

Teacher, Asperger Syndrome, narrative, inclusion.

\section{Palavras chave}

Professor, Síndrome de Asperger, narrativos, de inclusão.

Fecha de recepción: 24 de septiembre de 2014 / Fecha de aceptación: 31 de octubre de 2014

\footnotetext{
* México. Licenciada en Pedagogía por la Facultad de Estudios Superiores Aragón, Universidad Nacional Autónoma de México. Maestría en Pedagogía por la Facultad de Estudios Superiores Aragón, Universidad Nacional Autónoma de México. Investigadora sobre formación docente: Análisis de experiencias docentes sobre diversidad e inclusión en el aula. Trabajo con niños con problemas de aprendizaje en el Servicio de Atención Multidisciplinaria, niños con problemas de aprendizaje y sus familias. Maestra de educación primaria, "Colegio Monte Albán" y Esc.Sec.Tec. No24 "Ingeniero Víctor Bravo Ahuja".
} 
El siguiente texto se realizó a partir de mi experiencia como estudiante de la Licenciatura en Pedagogía; dando clases de regularización a un grupo de niños de mi colonia, me encontré en medio de las circunstancias que contaré a continuación.

Como docentes, todos nos imaginamos dando clase a un grupo de niños que captan un tema a la primera, tal vez a la segunda; imaginamos alumnos, niños que participarán, jugarán y ipor qué no?, te abrazarán, te llevarán una manzana o, qué sé yo, mil muestras de cariño y agradecimiento, de esas que siempre tienen los niños para con sus maestros. Sin embargo, ¿qué pasa si entre ellos existe un niño que no presta la atención mínima a lo que estás explicando?, ¿que no voltea a verte a los ojos, hace mil cosas mientras explicas, no juega con nadie y nunca permite que lo toques o abraces?, este tipo de alumnos sí existe, en mi caso, me encontré con Alex, un niño que de entrada pareciera no pensar, no necesitar, ni desear a nada, ni a nadie.

Pero no es así, un buen día apareciste ahí, con tu mirada, cual cordero perdido en la montaña; mil movimientos en tus manos mostraban tu gran inseguridad por estar con alguien que no fuera tu madre. Al saludarte solo recibí un choque fuerte en mi mano y, pronto, mil lágrimas y rabietas, así fue el primer día que te tuve como alumno, ¿̇abes?, ahora lo reconozco, en ese momento sentí mucho miedo y dentro de mí algo dijo ¡oh! ¡Por Dios! ¿Qué estoy haciendo?, ijamás podré hacer algo por él!, ¿qué hago?, ¿cómo le hablo?, ¿qué le enseño?, ¿cómo le enseño? Los días pasaban y pasaba lo mismo, pero el Ilanto y las rabietas disminuían; continuaba mi temor y estaba a punto de resignarme, cuando en la noche, dormitando, me puse a pensar qué haría si tuviera un hijo como Alex, pensé tantas cosas que desde la tarde siguiente tomé otra actitud, ya no de miedo, sino de asumir esto como un reto, y haría hasta lo imposible para conseguir aunque fuera un logro mínimo.

Una semana después ahí estabas, en la puerta, aún renuente de entrar, pero me viste y ya empezaste a asociar mi imagen como algo conocido; te tomé de la mano y te llevé hasta tu mesa de trabajo. Allí, mientras estabas junto a otros niños, pedí que hicieran un dibujo de ustedes mismos, te di la hoja y lo único que hiciste fue dobleces y dobleces sin sentido u orientación; te volví a dar una hoja más y pasó lo mismo, una tercera, que hiciste bola y la arrojaste bajo de la mesa como un cohete lanzado al espacio. Así pasaron varios días pero seguía insistiendo con esa actividad, uno y varios días más, mientras los demás niños hacían otras actividades, me propuse terminar esta contigo e insistiría hasta ver que podías hacerla.

Luego de 4 días logré que no deshicieras las hojas o las aventaras, pues, ahora, cada vez que lo intentabas las sujetaba con fuerza, tomaba tu mano y usando lápices de colores intentaba que vieras cómo éstos pintaban y que al usarlos podías hacer marcas en la hoja. Así fue que esto empezó a llamar un poco tu atención, ahora solo querías más y más colores y más hojas para hacer trazos sin sentido, joh no! ¿Y ahora qué? Pero, ya en estos momentos, ocurrió algo que jamás olvidaré: pedí una vez a la clase que se realizara un dibujo, y tú hiciste una especie de león; al verlo lo único que pude hacer fue felicitarte, expresar con gran emoción que tu dibujo era hermoso, que estaba muy bien; te alagué, y es que en tu carita se notaba una gran satisfacción, pronto, juntaste tus manitas $y$, contra tu pecho se hizo un sonido: ¡bum, bum, maetla! Nació una gran sonrisa en mi rostro, cual niño con juguete nuevo, y no pude evitar una lágrima de alegría en mis ojos, pues para mí todo aquello fue un sonido de amor, cargado de esa espontaneidad que no se puede ocultar.

Otro día decidí salir al patio con la clase para que se jugara con unos resortes y unas correas que tenía por ahí, fue muy difícil hacer que salieras con nosotros, solo te sentabas en aquella silla muy lejos de todos; pero fui por ti, tomé tu mano, te resistías, pero al fin logré sacarte. Intenté que tomaras la mano de uno de tus compañeros, pero lo golpeaste, así que quise llamarte la atención, o al menos explicarte que eso no se hacía, me agaché para estar a tu altura y hablarte a los ojos, ipero no!, todo fue en vano, no puede lograr que me miraras, volteabas a mil lados menos a mis ojos.

Continué la actividad con los demás niños mientras tú solo tocabas y tocabas las correas, te dije: toma una si quieres, pero solo pudiste aventarla lejos, tomé tu mano e hice que la recogieras; pedí a dos de tus compañeritos que sujetaran cada uno un extremo de la cuerda, asegurándome que al menos siguieras ahí parado, cerca 
de mí. Comencé a saltar una y otra vez y esto te causó mucha risa, hiciste muchos sonidos muy escandalosos, te dije que era tu turno, mientras solo seguías haciendo muchos movimientos con tus pies tratando de imitar mis saltos, jijijiji, aún lo recuerdo perfectamente.

Ingresamos nuevamente al salón, ahora veríamos los números, ese día enseñaría del 1 al 10. Olvidaba decir que me gusta tener música clásica como fondo durante las clases, lo menciono porque esto fue muy importante. Así, estaba explicando cuál era el 1, el 2, y así sucesivamente, cuando comenzaste a mover la cabeza diciendo que no, eso me llamó la atención, así que me acerqué y te pregunté ¿Alex, no qué? Solo señalabas la grabadora y de pronto hiciste muchos sonidos con tu boca, imitabas una trompeta, también movías tus manos como simulando un tambor.

Recordé que por ahí tenía guardado un tambor, lo saqué, te senté frente a mí y comencé a tocarlo, te pedí, sujetando tu mano, que también lo hicieras, diste golpes muy fuertes al tambor. Justo en este momento pensé en qué pasaría si te enseñaba a contar con un tambor, jijiji, parecería una locura, pero así lo hicimos. Te volví a sentar frente a mí y comencé a mostrarte cómo era el uno, lo mencionaba con voz fuerte y a la vez daba un golpe con el tambor, luego con el dos y así sucesivamente hasta el diez. Al instante hiciste lo mismo, me quitaste el palito que usábamos para golpear el tambor y, mientras temía que lo usaras para golpearte o golpear a alguien más, me diste una gran sorpresa: ¡intentabas contar!, incluso buscabas el mismo tono que usé la primera vez y dabas los golpes que correspondían a cada número, eso te encantó.

Al día siguiente, llegaste $y$, sin rabieta alguna, entraste simulando rodar por las paredes, una y otra vez hasta llegar a tu mesa de trabajo. Te sentaste y solo me hacías shhhhhh, volteabas tu mirada al suelo y simulabas tocar el tambor, jijiji. En ese momento pensé: vamos bien. Nuestra experiencia con el tambor hizo que al menos entraras sin oponer resistencia. Toda esa semana recordamos los números del 1 al 10, después del 10 al 20, y la técnica funcionó perfectamente. Te enamoraste de ese tambor, pero ahora el problema era a la salida, pues te lo querías llevar a casa, y ¿por qué no? Hable con tu mamá y le presté el tambor para que repasaras los números, estaba muy contenta y me decía todo el día querías estar con el tambor, estaba muy feliz de que ya supieras contar del 1 al 20.

En sesiones posteriores comenzamos a hacer sumas simples y pedí un ábaco a la clase, allí volvieron los problemas. Sacaste todas las bolitas del ábaco y me acerqué para decirte que eso no estaba bien, sin embargo, hiciste lo mismo con dos ábacos más y en casa hacías lo mismo; así que pensé en otra estrategia, usar frijoles blancos y negros. Me senté frente a ti y con voz fuerte y clara comencé por recordar los colores de los frijoles, después saqué el tambor, la suma era $3+2$, le di 3 golpes mientras, al tiempo, mencionaba el nombre del número, luego separé 3 frijoles negros; después di dos toques al tambor, mencioné el número 2 y separé dos frijoles blancos. Comenzaste a asociar y, en ese momento, te dije: ahora cuéntalo todo; di los 5 golpes seguidos haciendo la separación del 3 y del 2, también lo hice con los frijoles y sí, me dijiste: 5 Mali, porque escuchabas que tu mamá me Ilamaba Mary, jijiji, me diste una alegría inmensa.

Pasaron los días y notaba que poco a poco ibas dominando eso de los números, que tenías la habilidad, o al menos más herramientas, para el uso de las letras. Así, nuevas complicaciones y retos aparecían en nuestro trabajo, pero ahora las veía solo como grandes experiencias. No has sido un alumno más, has marcado mi vida al punto de hacerte la parte central de mi tesis de licenciatura.

Mientras hice mi tesis pude convivir con Alex y compartir todos los aspectos de su vida, dedicar días completos a su lado para poder llevar a cabo mi trabajo; en un inicio solo veía todo aquello como eso, un gran apoyo para sacar adelante la investigación, pero pronto, poco a poco, el niño y su familia acapararon cada uno de mis sentidos, emociones y sentimientos; así, pasamos por muchas cosas. Entre ellas no puedo evitar recordar el hecho que hasta ahora ha sido el más difícil de mi vida profesional.

En vísperas de las posadas, la mamá de Alex tuvo una caída que fue muy mal atendida, su pulmón se perforó y murió. Aún recuerdo todo esto con gran tristeza, esa noche llegó el papá de Alex a pedirme ayuda para explicarle al niño y a su hermana lo sucedido, se encontraba 
devastado y especialmente preocupado por saber cómo explicar a los niños lo que había pasado; lo reconozco, la verdad estuve a punto de decirle que yo tampoco sabía cómo hacerlo, pero, de pronto, algo en mi corazón me hizo agarrar fuerza y, al ver la desesperación del padre y la estima que tenía por la señora, me atreví.

Los niños se encontraban en casa de una vecina, llevaban allí ya un día sin ver a su mamá y preguntaban a cada instante por ella, cuando llegué Alex me reconoció pero, como presintiendo la mala noticia, al verme solo se alejó y se sentó en el sillón; Mariana insistía en preguntar a qué hora llegaría su mamá, ese nudo asfixiante en mi garganta no lo he vuelto a sentir en mi vida, allí pude entender que para Alex era mejor estar en ese su mundo tan oculto, interesante y diferente, para así no entender realmente el gran dolor de esa enorme pérdida.

Su papá decidió llevar al niño a un cuarto, allí tomé su cara e intenté verlo a los ojos, pero, un poco renuente, se escapaba; lo dejé tranquilo por un ratito y después, recordando que su mamá acostumbrar llevar a los niños todos los domingos a misa, y que son muy creyentes de la religión católica, le dije que su mamita se había ido con diosito; funcionó perfectamente. En ese momento Alex señaló un Cristo que había en el cuarto y solo decía: "mmm, sí mamita, mmm, iosito noooooo, cashaaaaa, cashaaaaaa"; le dije: "siiii Alex, mamita está en tu casa, pero ya se va a ir porque ya tiene que subir al cielo, ¿quieres ir a verla? Me dijo: "shiiiiii". Contesté: "Bueno, pero solo tantito... siiiii, porque ella ya se tiene que ir ¿sale? Aún recuerdo que todo aquello me impactó, creo que han sido los 5 minutos en los que Alex me demostró mayor madures y mayor atención.

Llegamos a su casa y todos los vecinos veían entrar a Alex, él no volteaba a ver a nadie, lo tomé del hombro, su papá lo hizo de la mano, lo acercamos al ataúd. Alex solo miraba y miraba a su mamá, sin decir palabra, volteó y, por primera vez, dirigió una mirada fija hacia mí, Ilena de gran tristeza como pidiéndome que no fuera verdad lo que estaba viendo. En ese momento pude comprender que un hecho así, en su mundo o en el nuestro, es simplemente la consagración de la tristeza.

Al ver sus ojitos sentía que no podía más, mis lágrimas estaban a punto de salir, ya había aguantado demasiado, pero debía ser fuerte para apoyar a Alex; corrió a su recámara, allí estaban sus dos tíos Ilorando, al verlos se acostó en la cama y comenzó a llorar y llorar. Pasaron varios minutos y después todo ocurrió con normalidad, volvió a pasar a lado del ataúd y entraba y salía de la casa con gran tranquilidad; salí, varios niños jugaban en la calle, pensé que Alex iría a jugar con ellos, pero no, se fue al otro extremo de la banqueta y solo observaba desde ahí todo el movimiento.

Al día siguiente fue el sepelio, su papá decidió que lo mejor era no llevar a los niños, yo dejé, como es menester, que tomara la decisión que creyera conveniente. A pesar de no contar con la experiencia necesaria para manejar una situación de esta índole, puedo decir que pude sacarla adelante; ya han pasado dos años desde la muerte de su mamá y Alex está muy tranquilo, solo dice que ella está con "iosito".

Por esta y muchas otras situaciones es que, como docentes, debemos de arriesgarnos a todo, tomar los miedos como retos y los problemas como experiencias. El mundo es tan diverso y lleno de seres tan valiosos como los niños con Síndrome de Asperger ${ }^{1}$, que ese pequeño

1 Es posible entender el Síndrome de asperger o Trastorno de Asperger, como: grosero y sostenido impedimento en la interacción social y patrones de conducta, intereses y actividades restringidos, repetitivos y estereotipados que ocurren en el contexto de un desarrollo cognitivo y del lenguaje preservado.

- Impedimento cualitativo en la interacción social, manifestado a través de por lo menos dos de las siguientes características:

1) Marcado impedimento en el uso de múltiples conductas no verbales, tales como mirada frente a frente, expresión facial, posturas corporales y gestos para regular la interacción social.

2) Falla para alcanzar relaciones con pares apropiadas al nivel del desarrollo.

3) Marcado impedimento para expresar placer por la felicidad de otra gente.

4) Falta de reciprocidad social o emocional.

- Patrones de conducta e intereses y actividades restrictas, repetitivas y estereotipadas.

- Falta de un retraso en lenguaje clínicamente significativo (por ejemplo, uso de palabras aisladas a los 2 años o de frases comunicativas a los 3 años).

- Falta de retraso de desarrollo cognitivo clínicamente significativo, tal como se manifiesta por el desarrollo de habilidades para desempeñarse solo acorde con la edad, conducta adaptativa y curiosidad por el entorno.

- No reúne criterios para otro trastorno profundo y difuso del desarrollo. 
sonido de amor hace que todo valga la pena. A través de mi investigación de maestría, titulada "Formación docente: experiencias y conceptualización sobre diversidad e inclusión en el aula mexicana", propongo que el docente, antes que basarse en los apoyos institucionales, debe usar su sentido humano, su compromiso con el otro, recurriendo en primera instancia a su intuición, complementándola con lo que implica el pacto con sus alumnos, que poco a poco hace que quiera formarse en cuanto a las problemáticas que se le presentan día a día, para así poder sacarlos adelante.

En México se siguen realizando y aplicando leyes y reformas educativas que no están de acuerdo con la situación actual del sistema educativo, especialmente con las necesidades de la población en cuanto a infraestructura, formación, especialización docente y planes y programas especializados, entre otras muchas cuestiones que hacen que las reformas sean simplemente inaplicables.

Muchas veces el docente se siente solo en su trabajo, siente que no es tomado en cuenta para situaciones en las que debería ser el principal actor, pues es quien lleva a cabo el trabajo diario. Existe una gran necesidad de los docentes por ser escuchados y apoyados por sus mismos colegas, es decir, por trabajar en equipo y poder compartir sus experiencias. Durante la investigación pude observar que los docentes enfrentan los retos de la educación inclusiva, en primera instancia, con miedos e incertidumbre, pero, a medida de que se va dando el trabajo con los niños, el docente, a través de su ética profesional y humana, busca sus propias estrategias para propiciar un verdadero proceso de enseñanza-aprendizaje.

El trabajo con la diversidad enriquece enormemente la formación y práctica docentes, ya que posibilita un nuevo estilo de enseñanza que abandone las viejas prácticas educativas, para optar por un trabajo solidario y en equipo en el que el docente investigue, comparta y sea cooperativo; se trata de buscar nuevos estilos de enseñanza-aprendizaje, nuevos modos de interacción con la diversidad y nuevos servicios de apoyo con otras funciones en la escuela; se trata de que se le dé valor a su labor, es decir, de que haya un nuevo modo de ser profesional de la enseñanza a partir de potenciar el aprendizaje multicultural, ya que el docente inclusivo debe preocuparse por hacer que los estudiantes diversos se sientan pertenecientes a una sociedad. Para ello, es necesario contar con escuelas en capacidad de atender las distintas necesidades, maestros especializados en las problemáticas específicas y, lo principal, docentes que tengan claro el objetivo y cuenten con la seguridad de que podrán sacar a sus alumnos adelante haciéndolos autónomos; deben tener confianza en que el miedo se vencerá y el reto se cumplirá.

\section{Referencias}

Williams, K. (1995). Comprender al estudiante con Síndrome de Asperger. Orientación para profesores. Michigan: Universidad de Michigan, p. 2. 


\section{Diálogo del conocimiento}

\section{Sentido humano para incluir.}

La sociedad en la que estamos inmersos aún insiste en tener acceso a información científica para abordar con ojos clínicos la diferencia; diagnósticos, rótulos, más recetas y tratamientos, para tener una sensación de mayor seguridad en la relación con el otro diferente. Si bien es necesario contar con información adecuada y oportuna para ofrecer al otro un trato de calidad, no es necesario enraizarse en patologías o buscar estandarizar procedimientos para trabajar con los seres humanos, pues lo más natural de nuestra especie es su diversidad y la diferencia que caracteriza a cada persona.

La inclusión educativa de personas en situación de discapacidad intelectual representa un gran reto para la educación de nuestro país, porque, a diferencia de la discapacidad sensorial, la mayoría de las veces, el asunto de reflexión no es solo de acceso y forma sino, además, de contenidos, cuestión que genera ansiedad en docentes y directivos.

Hoy en día, Información y contenidos ahogan la sociedad y deslumbra la facilidad de acceso en la era de la tecnología digital. ¿Para qué vamos a la Escuela? Pregunta neurálgica en el desarrollo de todo tipo de reflexiones pedagógicas. Para formar seres humanos que sepan vivir en comunidad, expresar sus sentimientos y opiniones, conocer y ejercer su ciudadanía, seres humanos que sean estimulados cognitiva y emocionalmente, que sean independientes en el mayor grado posible, que ejerzan el derecho a decidir, que sepan de derechos humanos, del cuidado de sí mismo, del cuidado del medio ambiente y se conviertan en personas felices son los objetivos prioritarios de la educación.

Maestros angustiados por los contenidos,ya que, raíces cuadradas y formulas químicas se convierten en ataduras para la espontaneidad y en potenciales obstáculos sí no se interpreta su pertinencia en la educación de los estudiantes en inclusión. Frecuentemente, la atención solo se centra en estándares de aprendizaje, en caminos únicos, en recursos únicos y en metas únicas en la formación de los escolares. Sí los caminos, recursos y metas fueran únicas para todos, sería esta una sociedad colmada de científicos químicos o de sociólogos; sin embargo, la riqueza de la sociedad está en su variedad de personas y la maravilla de cada uno de sus roles.

La inclusión educativa requiere reflexiones permanentes, procesos de sistematización y compartir saberes y experiencias constantemente, todo un acto comprometido académica y teóricamente, sin embargo su clave está, como lo menciona la autora Gisela Farias, en el Sentido Humano, la capacidad intuitiva, la sensibilidad, la flexibilidad cognitiva, la creatividad, dejar de lado formatos preestablecidos y decidirse a aventurar en la interacción con el otro. Su estudiante necesitó, más allá de sus conocimientos y teorías, de su sentido humano en el momento donde ella más tuvo al alcance orientarlo y acompañarlo; justamente cuando su figura fue más importante y significativa para él.

Los docentes no necesitamos demasiadas estrategias para trabajar con la inclusión educativa, requerimos familias con expectativas humanas sobre sus hijos y hermanos, comunidades bien dispuestas ante la novedad y, sobre todo, ver al otro como ser humano. Es decir, lo que esa disposición demande para mejorar su calidad de vida, de manera que logre ser un humano feliz. Es pertinente dejar de ver autistas para ver personas con autismo, pues esta condición no hace al ser humano, así como Diego no es un miope sino una persona con miopía, Andrea no es una autista sino una persona con autismo, cambiar el lenguaje y sobre todo cambiar el enfoque de la mirada contribuye a cambiar formas de pensar, actuar e interactuar en una escuela y una sociedad para todos y todas, que valore y celebre la Diversidad.

Stephany Campos Sarmiento 